\title{
Biological Evaluation of Ostrich Oil and Its Using for Production of Biscuit
}

\author{
Amany M. M. Basuny ${ }^{1}$, Shaker M. Arafat ${ }^{2}$, Hanaa M. Soliman ${ }^{3}$ \\ ${ }^{1}$ Biochemistry Dept., Faculty of Agriculture, Beni-Suef University, ${ }^{2}$ Olis \& Fats Dept., \\ Food Technology Research Institute, Agricultural Research Centre and ${ }^{3}$ Oils \& Fats \\ Dept., National Research Centre, Dokki, Egypt.
}

\begin{abstract}
$\mathrm{O}$ STRICH (Struthiocanelus) was used as a new source of animal fats. Where ostrich fat is a low price fat that separated from slaughtered ostrich. Some physical and chemical properties of the ostrich oil were determined. This oil was fractionated into liquid and solid fractions and some characteristics of these two fractions were determined. Ostrich oil and the two fractions (olein and stearin) were fed to rats for 8 weeks. The liver and kidney function tests (aspartate amino transferase, alanine amino transferase and alkaline phosphatase activities) and serum contents (total lipids, total cholesterol and low and high density lipoproteins) were measured. All of the aforementioned measurements are pointed to that the feeding of ostrich oil did not affect liver and kidney functions and serum contents. The total saturated fatty acids in ostrich oil, ostrich olein and ostrich stearin were $36.51,20.23$ and $73.93 \%$ respectively. On the other hand, the monounsaturated fatty acids in ostrich oil, ostrich oleisn and ostrich stearin were $46.75,57.37$ and $19.50 \%$ respectively. Finally the higher level of polyunsaturated fatty acids was recorded in ostrich olein $(21.70 \%)$ followed by ostrich oil (18.24\%) and the lowest level was recorded in ostrich stearin $(6.70 \%)$. Ostrich stearin was applied in biscuit manufacture in order to subrogate fat at ratios $(0.00,25.00,50.00$ and $75.00 \%)$. A sensory evaluation of biscuit was carried out. And the results revealed that baked biscuit characteristics were improved by replacement of margarine or hydrogenated oil with ostrich stearin.
\end{abstract}

Keywords: Ratite family, Ostrich oil, Fractionation, Biological evaluation.

\section{Introduction}

The Ratite family includes flightless birds with a flat, keel less breastbone (the keel is where the flight muscles connect). Most of their muscles are in their legs and thighs. Ratites usually feed on herbaceous plants, seeds, small rodents and insect [1].

This family includes three major species of birds namely ostrich, emu and rhea. Those birds are characterized by their low fat meat, low cholesterol and pretty leather [2,3]. Ratite oils represent about $15 \%$ of the whole body weight[4] and mainly used for cosmetics manufactures such as body lotion, creams, lipbalm and soap [5,6]. The ostrich, (Struthiocamelus) the world's largest and oldest bird (where those had been found more than 40 million years ago), is acclimated to live in barren land [7].

Ostrich oil is almost triglyceride lipids, and as human skin is so rich with triglycerides, it will be easy for it to absorb ostrich oil. Moreover this oil is free of phospholipids, and consequently it could highly penetrate human skin [8].

Ostrich oil can be used as antibacterial, antiinflammatory, and as an improver for skin and hair. It can be taken orally or by injection [9-12].

Ostrich oil is completely safe to be used for skin care and beauty products. In addition, it could be used for reducing itchy skin in pet animals, and to re-shine a pale coat. This oil may act as pain reliever when it used individually or combined with other ingredients and to normalize and improve human activities $[4,13]$.

The ostrich oil contains $28 \%$ saturated fatty acids, mostly as palmitic acid (20\%) and stearic acid $(8 \%)$. The polyunsaturated fatty acid is about $20 \%$ linoleic acid and $2 \%$ linolenic acid and the oil is high in oleic acid [10].

The aim of this work was to study physicochemical properties of ostrich oil, and to 
evaluate the tow different phases those separated from it. Also to study their safety as a new fat source. Finally, using of ostrich stearin for biscuit production instead of margarine or hydrogenated oil.

\section{Materials and Methods}

\section{Materials}

Ostrich fat (Sturuthiocanelus) was obtained from Faculty of Agriculture Al-Azhar University, and sunflower oil was obtained from SavolaSimMisr 10th Ramadan, Egypt.

All solvents used throughout the whole work were analytical grade and distilled before use: Alkaline phosphatase (AP), alanine aminotransferase (ALT), aspartate aminotransferase (AST), total cholesterol, HDLcholesterol, LDL-cholesterol and total lipids in serum were purchased from sigma (sigma-aldrich $\mathrm{GmbH}$, sternheim, germany).

\section{Methods}

Lipids extract

Ostrich Lipids were extracted from fatty tissues by dry rendering method[14]. The rendering process was carried out at $90^{\circ} \mathrm{C}$ for 3 hr. After cooling to $50^{\circ} \mathrm{C}$, the fats were filtered through Whatman No.1 filter paper and kept in brown bottles at $5^{\circ} \mathrm{C}$ until analysis.

\section{Fractionation of ostrich oils}

Ostrich oil was fractionated into two fractions namely olein as liquid fraction and stearin as a solid fraction[14].

\section{Analytical procedures}

Refractive index, melting point, acid value, peroxide value, iodine value, saponification number and unsaponifiable matter content were determined according to A.O.A.C[15], fatty acid methyl esters were prepared and analyzed by gas liquid chromatography [16], unsaponifiable matter composition of the samples were determined as described by Mordert[17] and oxidative stability was measured as a induction periods by using Rancimat method at $100^{\circ} \mathrm{C} \pm 2^{\circ} \mathrm{C}[18]$.

\section{Biscuit preparation}

Biscuits were prepared[14] using the following recipe: $28 \mathrm{~g}$ wheat flour, $24 \mathrm{~g}$ margarine, $24 \mathrm{~g}$ sugar, $13.55 \mathrm{~g}$ whole egg, $0.45 \mathrm{~g}$ baking powder and 10 $\mathrm{ml}$ defatted milk. To prepare the control biscuit, the sugar and margarine were creamed for $3 \mathrm{~min}$ at high speed in an Oster kitchen mixture (Model 972-26 H, Sunbeam Corporation, Milwaukee
Wisconsin, USA). The whole eggs and trace of vanillin were added and mixed in at the same speed for $2 \mathrm{~min}$. The flour, baking powder and defatted milk were added. To prepare the replacer biscuit, the margarine (fat weight basis in the formula) was replaced with ostrich stearin $(0.00,25.00,50.00$ and $75.00 \%$ ). The same order of mixing as described for the control was followed. Biscuit (100g) was weight into a greased and floured aluminum foil. Biscuit were baked at $180^{\circ} \mathrm{C}$ for $45 \mathrm{~min}$. After 5 min. the biscuit was removed from the pans and cooled for $60 \mathrm{~min}$, then wrapped in transparent film to avoid surface drying and stored at room temperature $\left(25^{\circ} \mathrm{C}\right)$ for $24 \mathrm{hr}$.

\section{Sensory evaluation}

Ten panelists performed sensory evaluation. Sensory quality attributes were evaluated using a point hedonic rating scale with 1 for dislike extremely to 9 for like extremely for each attribute. Biscuit was evaluated for appearance, crust and crumb colors, flavor, texture and overall acceptability. Biscuit was evaluated after baking by $24 \mathrm{hr}$. After cooling, biscuit was cut into $1.50 \mathrm{~cm}$ radial sections, placed in plastic bags, sealed and stored at room temperature $\left(25^{\circ} \mathrm{C}\right)$ until subjected to sensory analysis. Randomly coded samples were presented to the panelists in white plates and served one at a time. Samples were served to panelists in a room with partitions between each seat with overhead fluorescent light panelists were instructed to rinse their mouth with tap water before starting and between sample evaluation.

\section{Experimental animal}

Thirty two male rats of 60 days old with an average weight of $70 \mathrm{~g}$ were obtained from the Faculty of Veterinary Medicine. Cairo University, Giza, Egypt. The animals were fed on a basal diet for 7 days as an adaptation period. The basal diet was formulated according to A.O.A.C[15] and consisted of casein (15\%),corn oil (10 $\%)$,cellulose $(5 \%)$, salt mixture $(4 \%)$, vitamin mixture $(1 \%)$ and starch $(65 \%)$. Water was available as needed.

\section{Feeding experiment}

The animals were divided into 4 groups, each group contains 8 rats to evaluate the effect of feeding on basal diet containing $10 \%$ of fresh ostrich oil, olein fraction and stearin fraction orally compared with control which contained corn oil. Blood samples were drawn from rats eyes weekly for 8 weeks, then centrifuged individually to separate serum which was kept in deep- freezer 
until analysis.

\section{Serum analysis}

ALT, AST and AP activities were measured[1921]. Also, the level of serum cholesterol, low and high density lipoproteins, total lipids and triglycerides were determined [22- 25].

\section{Statistical analysis}

Data analysis

At least three replications for each oil sample were performed with each test. The averages and standard deviation were calculated by statistical analysis using SPSS program.

\section{Results and Discussion}

Physicochemical properties of ostrich oil, ostrich olein and ostrich stearin

Table 1 shows the physicochemical properties of ostrich oil and the two fractions. The moisture content and volatile matter were the same for the ostrich oil and the two fractions $(0.01 \%)$. while, refractive index of ostrich oil and two fractions at $40^{\circ} \mathrm{C}$ were $1.4563,1.4586$ and 1.4472 respectively. On the other hand, ostrich oil and two fractions color were under the limitation of Egyptian Standard Specification[26], the red color was 2.02, 2.10 and 2.00 respectively and the yellow was 35.01 for all. Melting point of ostrich oil $\left(25.50^{\circ} \mathrm{C}\right)$ was lower than that of ostrich stearin $\left(54.00^{\circ} \mathrm{C}\right)$ and higher than that of ostrich olein $\left(20.00^{\circ} \mathrm{C}\right)$. Generally, ostrich oil was found to be semi-solid at room temperature.

Acid value of ostrich oil $(0.10 \%)$ was higher than the two fractions $(0.09$ and 0.08$)$. The peroxide value of ostrich oil was 0.90 while that of ostrich olein and ostrich stearin were 0.85 and 0.87 meq./kg oil respectively. Moreover ostrich oil shows higher iodine value (79.01 gI2) than that of the two fractions (58.00, and 49.00). Saponification number and unsaponifiable matter of ostrich oil (205.00 and $1.5 \%$; respectively) were higher than those of two fractions shown in Table 1. These results are agreement with that reported by Mordert [17].

\section{Fatty acid composition of ostrich oil}

Gas liquid chromatography was used to determine the fatty acid composition of ostrich oil, ostrich olein and ostrich stearin, the results are tabulated in Table 2. In ostrich oil and ostrich olein the oleic acid is found to be the dominant unsaturated fatty acid, which represents 46.75 and $57.37 \%$ respectively but in ostrich stearin it was $(19.50 \%)$. While the dominant saturated fatty acid in ostrich oil and ostrich stearin was palmitic acid (28.50 and $55.83 \%)$ respectively but in ostrich olein it was $(17.50 \%)$. The total saturated fatty acids in ostrich oil, ostrich olein and ostrich stearin were $(36.51,20.23$ and $73.93 \%)$ respectively. On the other hand, the monounsaturated in ostrich oil, ostrich oleisn and ostrich stearin were (46.75, 57.37 and $19.50 \%$ ) respectively. Finally the higher level of polyunsaturated fatty acids was recorded in ostrich olein $(21.70 \%)$ followed by ostrich oil $(18.24 \%)$ and the lowest level was recorded in ostrich stearin $(6.70 \%)$. The results are in agreement with that reported by other authors[14-27].

\section{Unsaponifiable matter components of ostrich oil}

Gas liquid chromatography was used in order to analyze the hydrocarbons and sterols in the unsaponifiable matter of ostrich oil, ostrich olein and ostrich stearin. Data are elucidated in Table 3. The major hydrocarbon in ostrich oil and in the two fractions is C28. Concerning the sterols, B-sitosterol is the major sterols component in ostrich oil and in the two fractions. Cholesterol

TABLE 1. Physicochemical properties of ostrich oil, ostrich olein and ostrich stearin.

\begin{tabular}{lccc}
\hline \multicolumn{1}{c}{ Parameter } & Ostrich & Ostrich olein & Ostrich stearin \\
\hline Moisture content \% & & & \\
Refractive index at $40^{\circ} \mathrm{C}$ & $0.01 \pm 0.001$ & $0.01 \pm 0.001$ & $0.01 \pm 0.001$ \\
Melting point $\left({ }^{\circ} \mathrm{C}\right) \quad 1.4563 \pm 0.001$ & $1.4586 \pm 0.001$ & $1.4472 \pm 0.001$ \\
Color Yellow $\quad 25.50 \pm 1.20$ & $20.00 \pm 1.02$ & $54.00 \pm 3.45$ \\
$\quad$ Red & $35.01 \pm 2.39$ & $35.01 \pm 2.39$ & $35.01 \pm 2.39$ \\
Acid value (as oleic acid) & $2.02 \pm 0.11$ & $2.10 \pm 0.15$ & $2.00 \pm 0.13$ \\
Peroxide value (meq./kgoil) & $0.10 \pm 0.001$ & $0.09 \pm 0.001$ & $0.08 \pm 0.001$ \\
Iodine value (Hanus) & $0.90 \pm 0.19$ & $0.85 \pm 0.18$ & $0.87 \pm 0.18$ \\
Saponification number & $79.01 \pm 5.67$ & $58.00 \pm 3.96$ & $49.00 \pm 3.34$ \\
Unsaponifiable matter (\%) & $205.00 \pm 10.11$ & $200.00 \pm 9.91$ & $201.00 \pm 9.81$ \\
\hline Datre & $1.50 \pm 0.10$ & $1.20 \pm 0.09$ & $1.00 \pm 0.71$ \\
\hline
\end{tabular}

Data are expressed as mean \pm SD values given represent means of three determinations. 
TABLE 2. Fatty acids composition of ostrich oil, ostrich olein and ostrich stearin.

\begin{tabular}{cccc}
\hline Fatty acid (\%) & Ostrich & Ostrich olein & Ostrich stearin \\
\hline $\mathrm{C}_{12: 0}$ & $0.81 \pm 0.17$ & $0.30 \pm 0.01$ & $0.43 \pm 0.01$ \\
$\mathrm{C}_{14: 0}$ & $1.00 \pm 0.001$ & $0.13 \pm 0.001$ & $0.17 \pm 0.001$ \\
$\mathrm{C}_{16: 0}$ & $28.50 \pm 1.24$ & $17.50 \pm 0.82$ & $55.83 \pm 3.96$ \\
$\mathrm{C}_{18: 0}$ & $6.20 \pm 0.54$ & $2.30 \pm 0.18$ & $17.50 \pm 0.62$ \\
$\mathrm{C}_{18: 1}$ & $46.75 \pm 3.17$ & $57.37 \pm 4.22$ & $19.50 \pm 0.93$ \\
$\mathrm{C}_{18: 2}$ & $13.29 \pm 0.72$ & $15.40 \pm 0.69$ & $6.10 \pm 0.51$ \\
$\mathrm{C}_{18: 3}$ & $4.95 \pm 0.33$ & $6.30 \pm 0.53$ & $0.60 \pm 0.01$ \\
Saturated fatty acid (\%) & $36.51 \pm 2.56$ & $20.23 \pm 1.00$ & $73.93 \pm 5.87$ \\
Monounsaturated (\%) & $46.75 \pm 3.58$ & $57.37 \pm 4.98$ & $19.50 \pm 0.89$ \\
Polyunsaturated (\%) & $18.24 \pm 0.77$ & $21.70 \pm 1.34$ & $6.70 \pm 0.53$ \\
\hline
\end{tabular}

Data are expressed as mean \pm SD values given represent means of three determinations.

TABLE 3. Unsaponifiable matter (\%) composition of ostrich oil ostrich olein and ostrich stearin.

\begin{tabular}{lccc}
\hline \multicolumn{1}{c}{ Compounds } & Ostrich & Ostrich olein & Ostrich stearin \\
\hline $\mathrm{C}_{14: 0}$ & Hydrocarbons: $\mathrm{C}_{12: 0}$ & $2.00 \pm 0.10$ & $2.01 \pm 0.01$ \\
$\mathrm{C}_{16: 0}$ & $2.05 \pm 0.11$ & $1.90 \pm 0.11$ & $2.05 \pm 0.01$ \\
$\mathrm{C}_{18: 0}$ & $2.14 \pm 0.09$ & $2.50 \pm 0.16$ & $1.88 \pm 0.11$ \\
$\mathrm{C}_{20: 0}$ & $2.13 \pm 0.18$ & $3.66 \pm 0.21$ & $3.81 \pm 0.22$ \\
$\mathrm{C}_{22: 0}$ & $4.20 \pm 0.23$ & $7.50 \pm 0.51$ & $6.00 \pm 0.45$ \\
$\mathrm{C}_{24: 0}$ & $6.50 \pm 0.43$ & $1.92 \pm 0.12$ & $1.86 \pm 0.13$ \\
$\mathrm{C}_{26: 0}$ & $1.93 \pm 0.10$ & $7.28 \pm 0.63$ & $7.45 \pm 0.51$ \\
$\mathrm{C}_{28: 0}$ & $7.30 \pm 0.65$ & $10.00 \pm 0.88$ & $9.81 \pm 0.81$ \\
Squalene & $10.20 \pm 0.89$ & $15.80 \pm 0.97$ & $15.00 \pm 0.71$ \\
$\mathrm{C}_{30: 0}$ & $16.65 \pm 0.92$ & $3.50 \pm 0.24$ & $1.50 \pm 0.12$ \\
Sterols: Choleterol & $2.20 \pm 0.12$ & $2.60 \pm 0.19$ & $2.71 \pm 0.11$ \\
$\beta$ - sitosterol & $3.60 \pm 0.18$ & $3.41 \pm 0.17$ & $3.33 \pm 0.23$ \\
Stigmasterol & $3.50 \pm 0.16$ & $27.50 \pm 1.62$ & $20.11 \pm 0.95$ \\
Campasterol & $28.50 \pm 1.55$ & $3.20 \pm 0.31$ & $2.30 \pm 0.11$ \\
\end{tabular}

Data are expressed as mean \pm SD values given represent means of three determinations.

content in ostrich oil, ostrich olein and ostrich stearin were $3.50,3.41$ and $3.33 \%$ respectively.
Sensory evaluation of biscuit

Table 4 shows that biscuit prepared from

TABLE 4. Sensory evaluation of biscuit produced from ostrich stearin.

\begin{tabular}{lcccc}
\hline Parameters & \multicolumn{4}{c}{ Replacer levels (\%) } \\
\cline { 2 - 5 } & 0.00 & 25.00 & 50.00 & 75.00 \\
\hline Appearance & $8.30 \pm 0.54$ & $8.80 \pm 0.59$ & $7.70 \pm 0.49$ & $6.50 \pm 0.41$ \\
Crust color & $8.70 \pm 0.55$ & $8.80 \pm 0.56$ & $7.60 \pm 0.48$ & $6.60 \pm 0.39$ \\
Crumb color & $8.60 \pm 0.50$ & $8.80 \pm 0.54$ & $7.50 \pm 0.50$ & $6.90 \pm 0.45$ \\
Flavor & $8.50 \pm 0.53$ & $8.70 \pm 0.51$ & $7.60 \pm 0.49$ & $6.70 \pm 0.44$ \\
Texture & $8.80 \pm 0.55$ & $8.90 \pm 0.62$ & $7.90 \pm 0.48$ & $6.50 \pm 0.45$ \\
Overall acceptability & $8.70 \pm 0.50$ & $8.90 \pm 0.55$ & $7.80 \pm 0.48$ & $7.60 \pm 0.49$ \\
\hline
\end{tabular}

Data are expressed as mean \pm SD values given represent means of three determinations. 
ostrich stearin had significantly $(\mathrm{P}>0.05)$ improved flavor, texture and general acceptability more than that of control.

Influence of feeding of ostrich oil, olein and stearin fractions on the activity of serum alanine aminotransferase, aspartate aminotransferase and alkaline phosphatase of rats

Figures 1, 2 and 3 show that during the whole experiment ( 8 weeks) the activities of ALT, AST and AP for control rats were slightly increased. While there were significant increases for that group feeding on stearin fraction. Moreover, there were non significant changes for those groups feeding on ostrich oil and olein fraction.

Influence of feeding of ostrich oil, olein and stearin fraction on serum lipid profile Serum total lipids

The results in Fig. 4 illustrate that throughout the whole experiment the total lipids for control rats have non-significant differences. While there were significant and gradual increases in total lipids for that group feeding on stearin fraction. On the other hand feeding on ostrich oil and olein fraction induced non-significant rise in total lipids of rat serum.

Serum total cholesterol and low density lipoprotein cholesterol ( $L D L-C)$

Figures 5 and 6 show the levels of serum total cholesterol and low-density lipoprotein cholesterol for all the experimental animals.

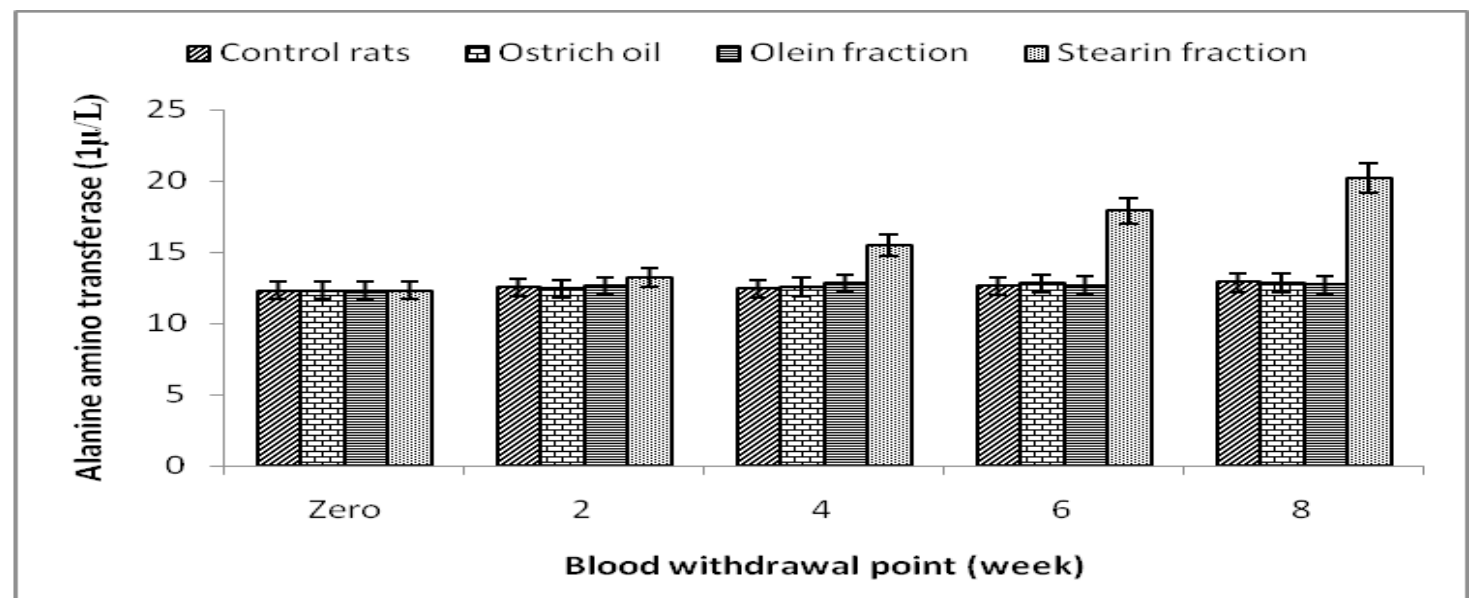

Fig. 1. Influence of feeding of ostrich oil, olein and stearin fractions on the activity of serum alanine amino transferase. Data are expressed as mean \pm SD values given represent means of three determinations.

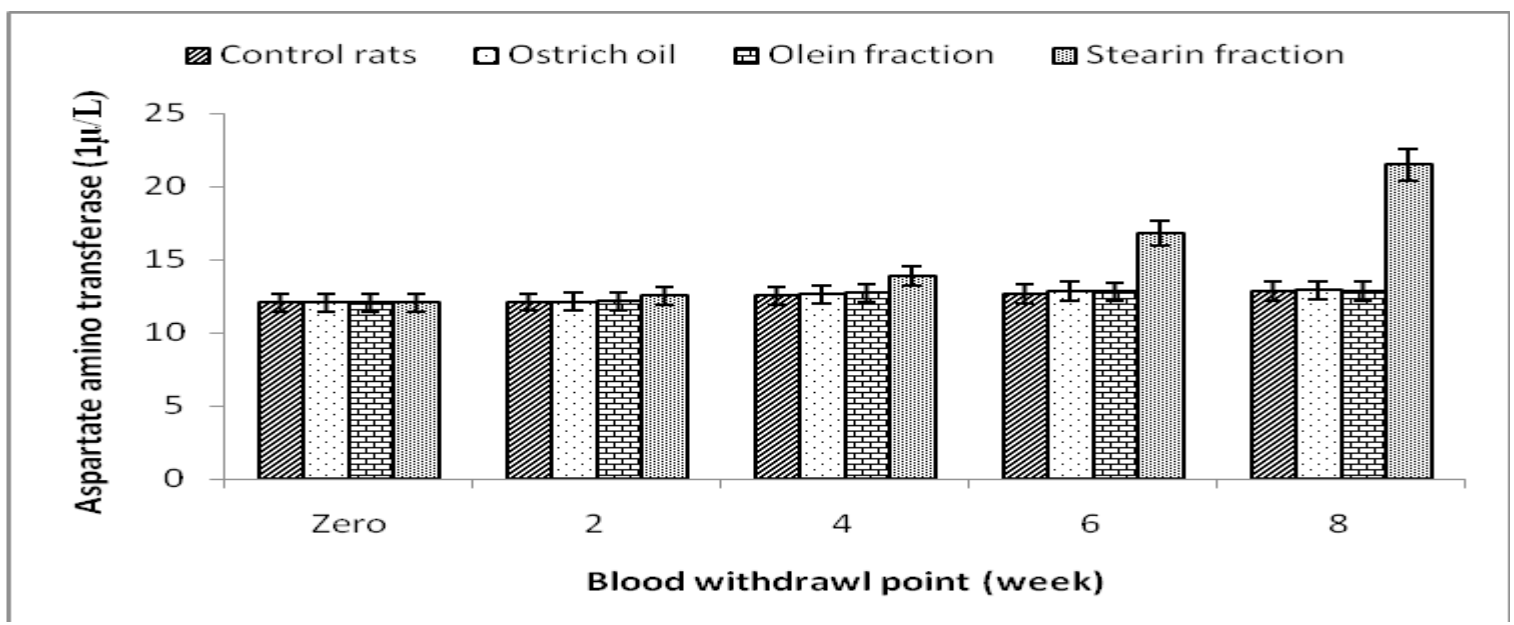

Fig. 2. Influence of feeding of ostrich oil, olein and stearin fractions on the activity of serum aspartate amino transferase. Data are expressed as mean $\pm \mathrm{SD}$ values given represent means of three determinations. 


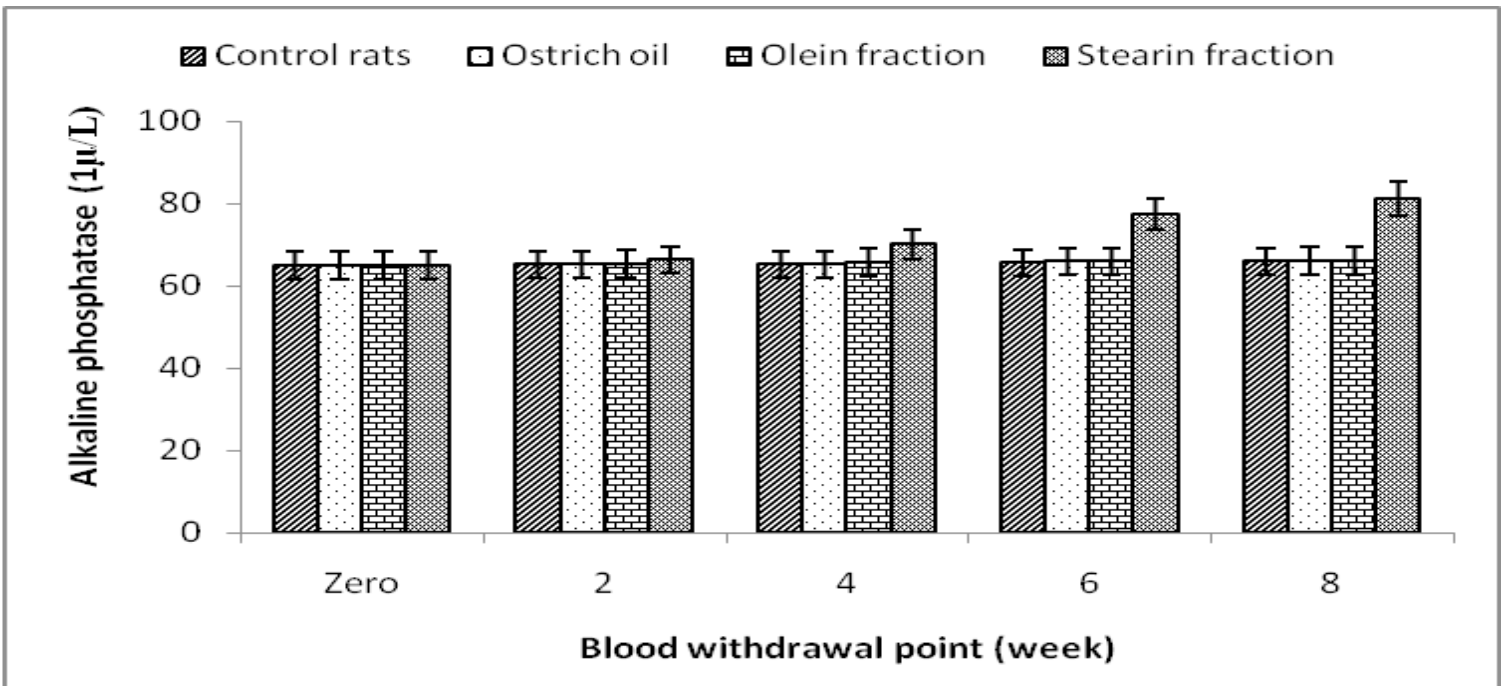

Fig. 3. Influence of feeding of ostrich oil, olein and stearin fractions on the activity of serum alkaline phosphatase. Data are expressed as mean \pm SD values given represent means of three determinations.

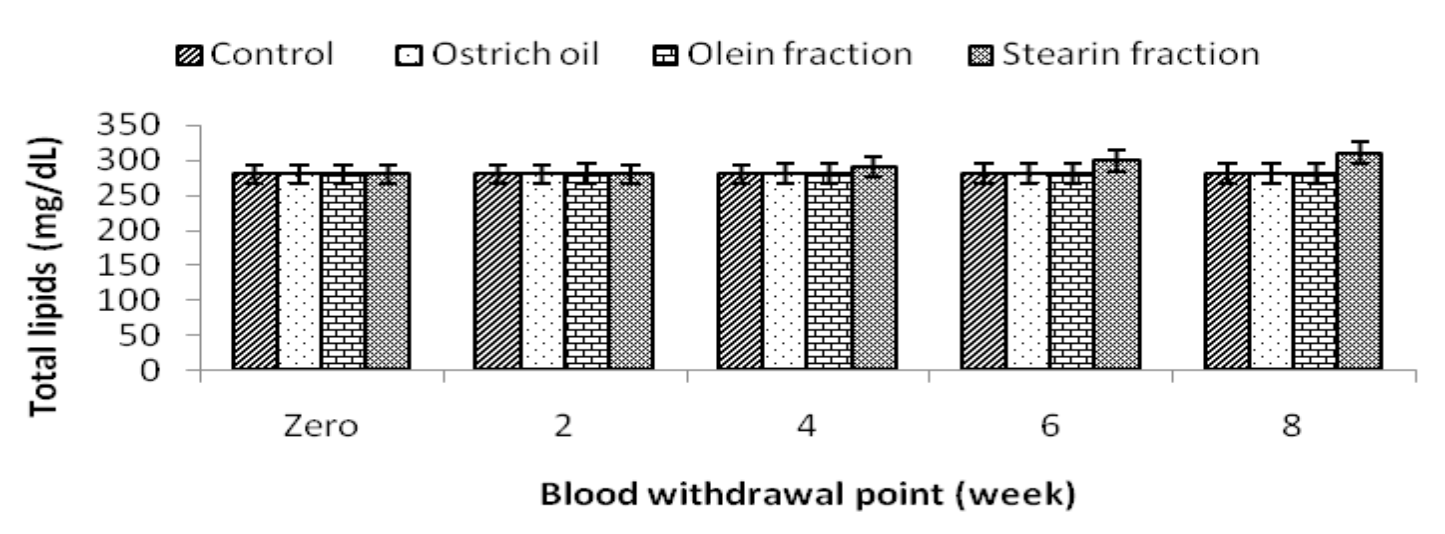

Fig. 4. Influence of feeding of ostrich oil, olein and stearin fractions on the activity of serum total lipids. Data are expressed as mean $\pm \mathrm{SD}$ values given represent means of three determinations.

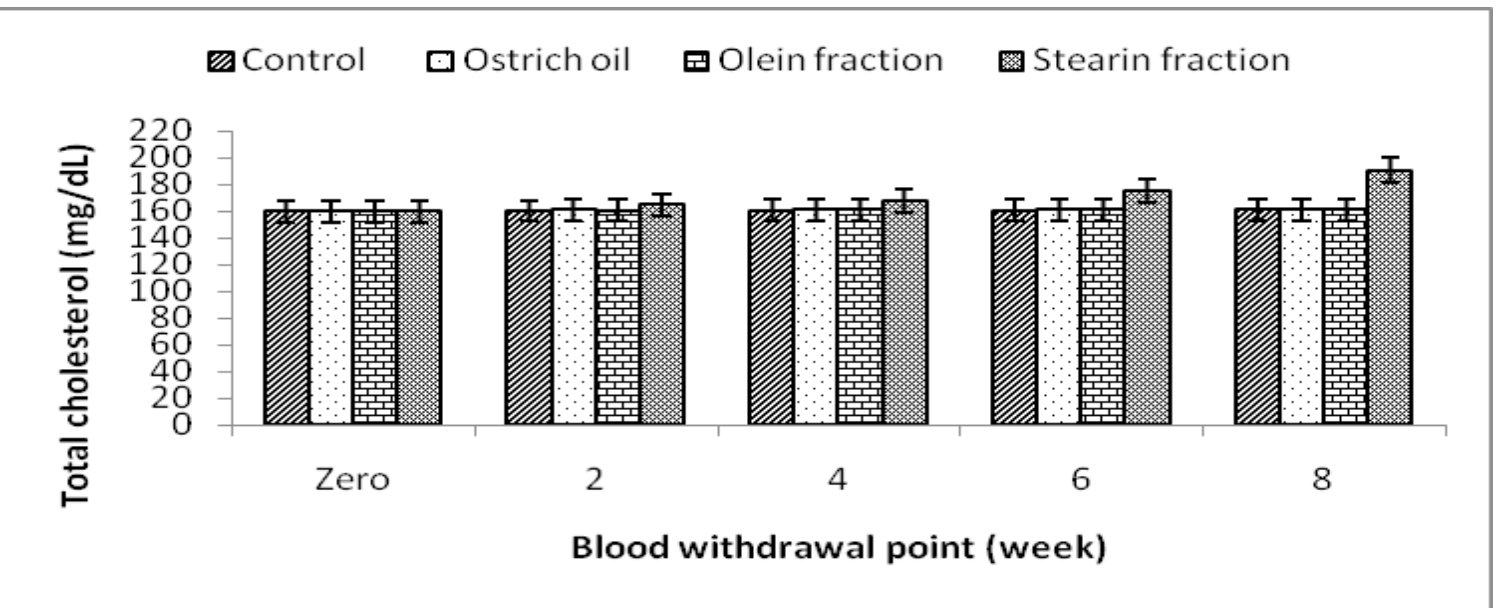

Fig. 5. Influence of feeding of ostrich oil, olein and stearin fractions on the activity of serum total cholesterol. Data are expressed as mean \pm SD values given represent means of three determinations.

Egypt. J. Chem. 60, No.6 (2017) 


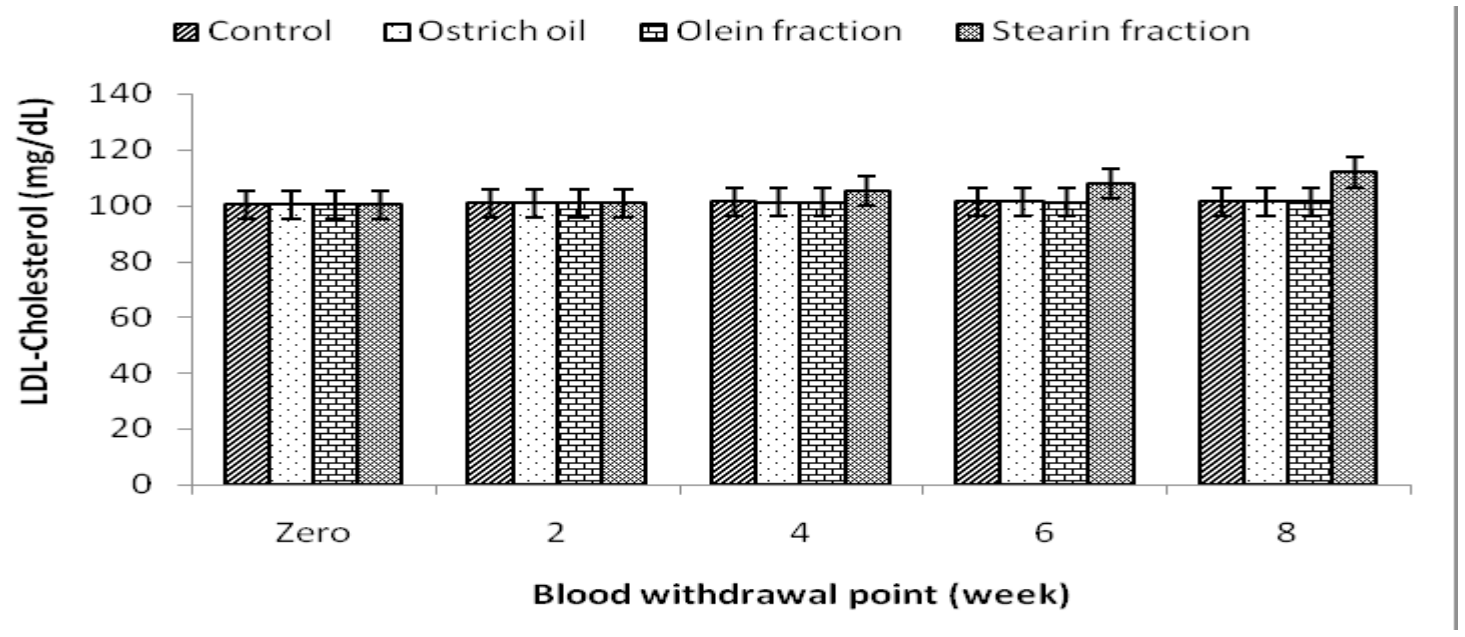

Fig. 6. Influence of feeding of ostrich oil, olein and stearin fractions on the activity of serum LDL-Cholesterol. Data are expressed as mean \pm SD values given represent means of three determinations.

During the entire experiment, total cholesterol levels and LDL-C for control rats and rats feeding on ostrich oil and olein fraction there were non significant increases. While, significant increases are observed for rats feeding on stearin fraction.

Serum high density lipoprotein cholesterol $(H D L-C)$

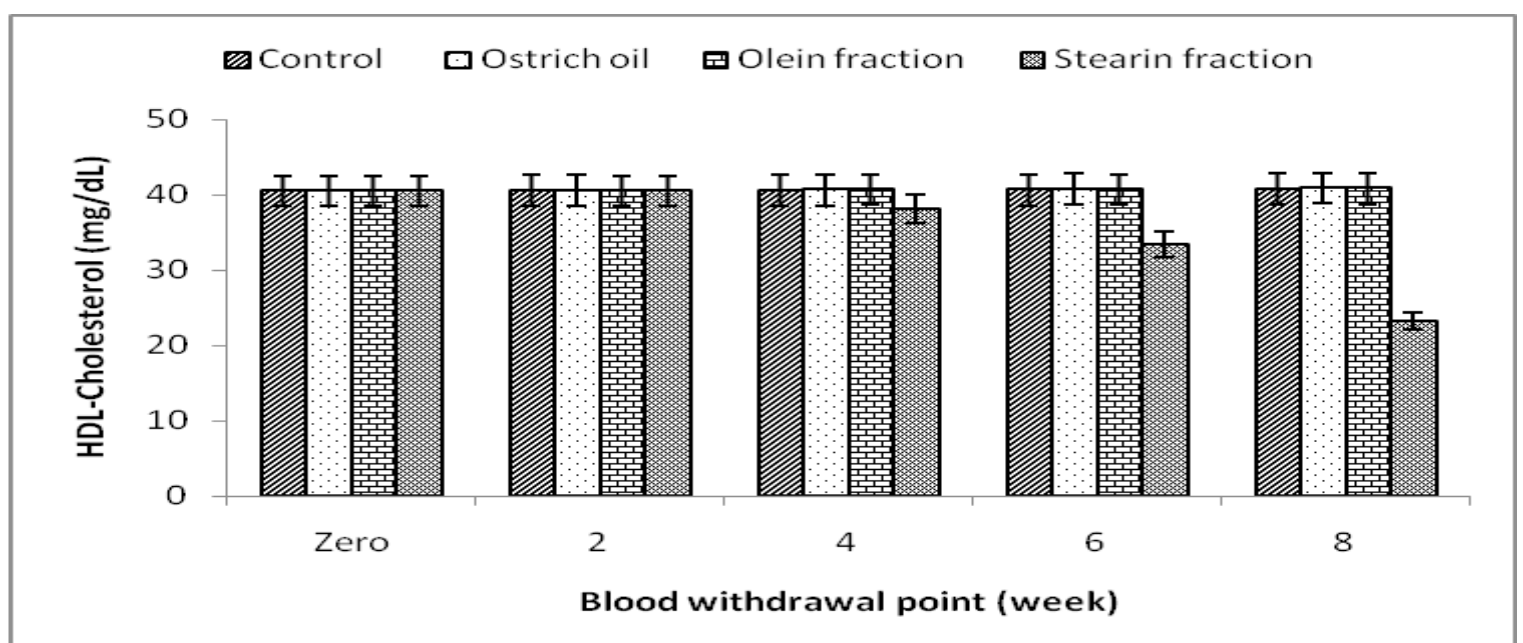

Fig. 7. Influence of feeding of ostrich oil, olein and stearin fractions on the activity of serum HDL-Cholesterol. Data are expressed as mean \pm SD values given represent means of three determinations.

The data (Fig.7) for levels of HDL-C during the entire experiment ( 8 weeks) for the control rats and rats feeding of ostrich oil and olein fraction showed non-significant changes. On the contrary, gradual increases is reported for rats feeding on stearin fraction.

\section{Rrefrences}

1. Olaf K. H. and Agnieszka W., Technological and nutritional properties of ostrich, emu, and rhea meat quality. J. Vet. Res, 60, 279-286(2016).
2. Gegener L., Ratite Production: Ostrich, Emu and Rhea, Livestock production Guide, ATTRANational Sustainable Agriculture Information Services(2001).

3. Hernandez E., Pocessing of ratite oils, J. Am. Oil Chem. Soc. Newsletter (9), 100-102(2003).

4. Animal Production Research Institute, Agriculture research centre, Giza, Egypt. Bulletin No. 861(2004).

Egypt. J. Chem. 60, No.6 (2017) 
5. Grompone A. M, Irigaray B. and Gil M., Uruguayan nandu (Rhea americana oil: Acomparison with emu and ostrich oils, J. Am.OilChem. Soc. 82 (9), 687689(2005).

6. Sethi A.P.S., Rearing emu birds at GADVASU. Personal Communication (2015).

7. Chris P. and Slates C., Uses and benefits of emu oil. Nutrition \& Food Science, 38- 42(1999).

8. Margret C., Uses and benefits of emu oil Nutrition \& Food Science, 38-42(2003).

9. Brown, M. A., Craig- Schmidt and Smith P. C., Fatty acid composition of emu (Dromaiusnavaehollandiae) oil, INFORM, 6, 470(1995).

10. Krawezyk T., Emu: premier oil bird, INFORM, 8, 246-252(1997).

11. Craig-Schmidt M. C., Ratite oils: composition and claimed beneficial effects, Lipid Technol. Newsletter (8), 80- 83 (1999).

12. Sales J. and Franken L., Ostrich fat, Australian Ostrich Association Journal, 37, 39-45(1996).

13. Knowlton J. and Pearce S., Handbook of Cosmetic Science and Technology, Elsevier Editorial, Oxford, UK(1993).

14. Baileys, Industrial Oil and Products. 5 th ed. Edited by Y. U, Hui, Vol. 1, Wiley Internet. Science Publication John Wiley and Sons, Inc., P20(1996).

15. A.O.A.C. Official Methods of Analysis Association of official Analytical Chemists, $20^{\text {th }}$ Ed Association International, Arlington, Virginia, USA(2016).

16. Farag R. S., Abdel-Rahim E. A., Elsharabasy A. M., Hewedy F.M. and Ragab A. A., Biochemical studies on lipids of hens egg during incubation. Seifen de-fette, Wachse 100, 63(1984).

17. Mordert F., Comparison and study of methods of obtaining unsaponifiable matter. J. Crops Grasses, 6, 389-397(1968).

18. Evangelisti F., Zunin P., Tisconia E., Petacchi R., Drava G. and Lanteri S., Stability to oxidation of virgin olive oils as related to olive condition: study of polar compounds by chemometric methods, $J$. Am. Oil, Chem. Soc. 74 (8), 117(1997).

19. Kachmar J. F. and Moss D. W., Fundamentals Of Clinical Chemistry, N. Tiez ed., pp 680, W. B. Saunders Co., Philadelphia, PA(1976)

20. Bergmeyer H. U. and Harder M., A colorimetric method determination of serum glutamic oxalacetic and glutamic pyruvic transaminase. Clinical Biochemistry, 24, 28 - 34(1986).

21. Varley H., Gewenlock A. and Bell M., Practical Clinical Biochemistry, Vol. 1, 5thedn. PP. 741, 897, London: William Heinemen Medical Books $\operatorname{Ltd}(1980)$.

22. Roechlau P., Betnt E. and Gruber W. L., Kinetics of the cholesterol. sulfuric acid reaction. A fast kinetic method for serum cholesterol, Clin. Chem. Biochem. 12, 403-408(1974).

23. Assmann G., Cholesterol determination in high density lipoprotein separated by three different methods. Internist, 20, 559 - 604 (1979).

24. Frings C. S. and Dunn R. T., Colorimetric method for determination of total serum lipids based on the sulpho-phospho-vanillin reaction, Am. J. Clin. Pathol. 53, 89-91(1979).

25. Wahelefed A. W., In Methods of Enzymatic Analysis. Nol. 5, Ed. Academic. Press, New York. (1974).

26. Egyptian Standard Specification Egyptian standard (49/1993) for Oils Egyptian Organization for Standardization and quality Control, Ministry of Industry, Cairo, Egypt(1993).

27. Mandal A. B., Wadhwa M. and. Bakshi M.P.S., Animal Feeding - Concepts and Practices, Published by Satish Serial Publishing House, Azadpur, Delhi-110033, India(2016).

(Received 10/7/2017 ; accepted 25/9/2017 


\title{
التقييم البيولوجى لزيت النعام واستخدامه فى انتاج بسكويت
}

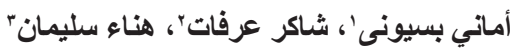

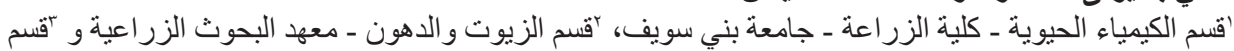

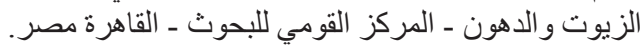

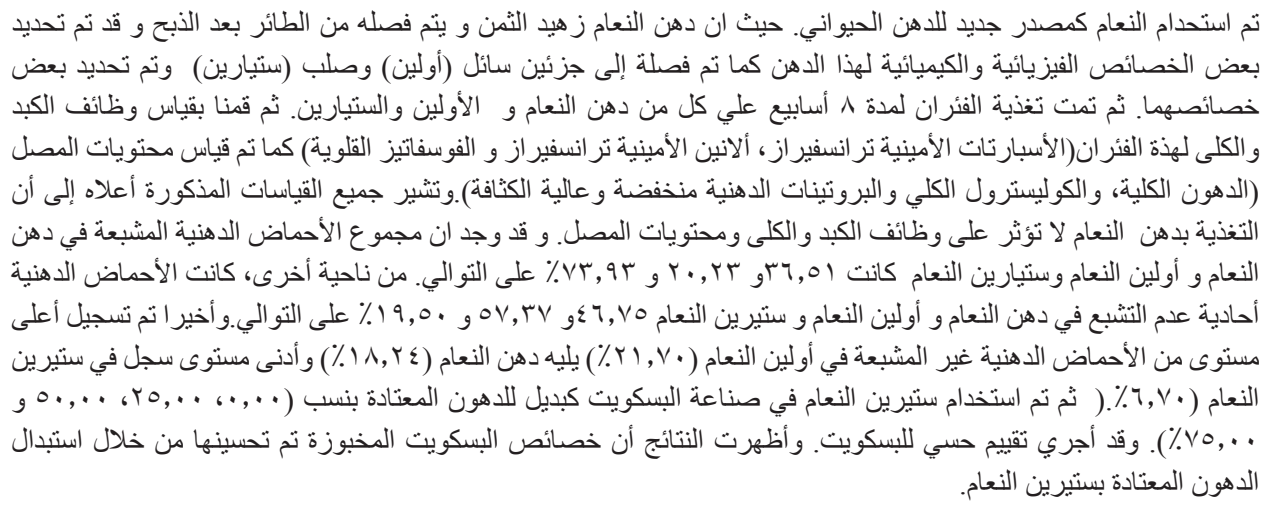

